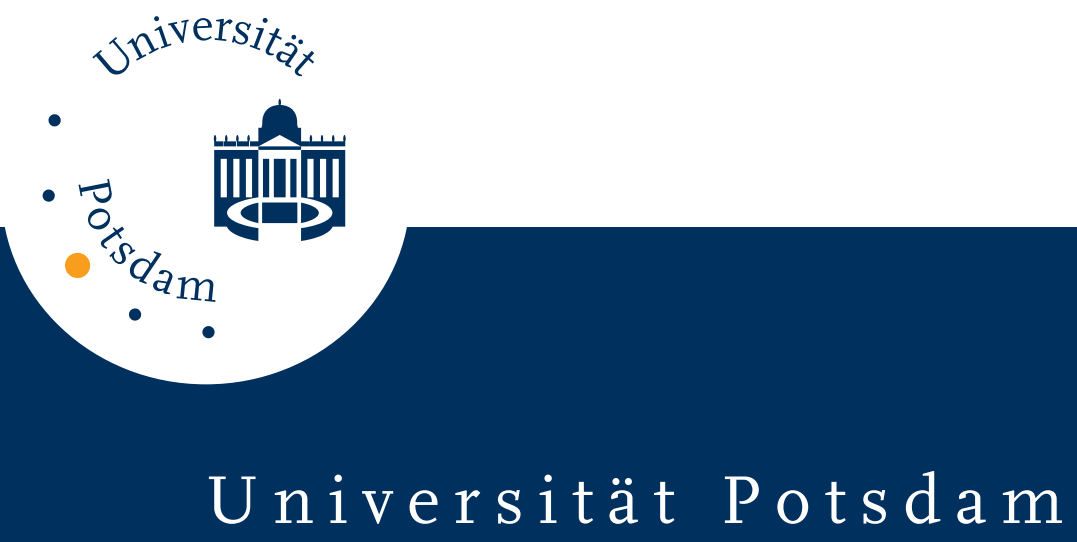

Barbara Krahé

\title{
Faking personality profiles on a standard personality inventory
}

first published in:

Personality and Individual Differences, 10 (1989) 4, p. 437-443

Postprint published at the Institutional Repository of Potsdam University:

In: Postprints der Universität Potsdam

Humanwissenschaftliche Reihe ; 84

http://opus.kobv.de/ubp/volltexte/2009/3448/

http://nbn-resolving.de/urn:nbn:de:kobv:517-opus-34486

Postprints der Universität Potsdam

Humanwissenschaftliche Reihe ; 84 


\title{
FAKING PERSONALITY PROFILES ON A STANDARD PERSONALITY INVENTORY
}

\author{
Barbara KrahÉ* \\ Department of Psychology, University of Mainz, F.R.G.
}

(Received 15 April 1988)

\begin{abstract}
Summary-A study is reported which investigates the fakeability of personality profiles as measured by a standard personality inventory, the Freiburger Persönlichkeitsinventar (FPI). Unlike previous studies investigating laypersons' ability to fake a global good or bad impression, the present study examined individuals' ability to fake a specific personality profile. Four groups of subjects were instructed to fake their FPI scores so as to present themselves as high vs low scorers on the "social orientation" dimension or high vs low scorers on the "achievement orientation" dimension. The results clearly demonstrate that subjects are successful in manipulating their scores on the critical dimensions according to instruction. Moreover, they also fake related scales in a way that corroborates the intended image of a person with a high (or low) achievement (or social) orientation. The overall pattern of results reveals that subjects were able to distort their responses in a way that reflects their intuitive understanding of the dimensional structure of the FPI. The implications of the present findings for the use of personality inventories as valid diagnostic instruments are discussed.
\end{abstract}

The application of personality inventories is standard practice in a variety of diagnostic settings. The idea is that these instruments can provide the diagnostician with information about the tested individual which enables him or her to make an informed decision about the problem at hand. However, they can only serve the intended purpose under the premise that a person's responses are an undistorted, i.e. meaningful reflection of his or her (self-perceived) personality. This premise may be met in situations where the person tested is either interested in receiving genuine feedback or relatively indifferent about the outcome of the test. Yet there are many situations where the person has a vested interest in obtaining a certain test result in preference over another. Malingerers are keen on portraying themselves as physically or mentally unfit, job applicants would generally try hard to create an image of themselves as well-adjusted and capable personalities, prisoners due to be released on parole have every reason to present themselves as emotionally stable and harmless (e.g. Wilcox and Krasnoff, 1967). It is in diagnostic contexts such as these that the suitability of self-report inventories for yielding reliable and valid information about individual personality appears to be most critical (see Berg, 1967; Eysenck, Nias and Eysenck, 1971).

A number of studies have shown that self-report personality inventories are highly susceptible to a variety of response biases, such as lying, social desirability, extremity and acquiescence (see Furnham, 1986, for a review). Many of these studies have compared personality scores obtained from groups of subjects who received different instructions before completing the respective inventory. A common approach has been to compare subjects instructed to "fake good", i.e. present the best impression of themselves, with those instructed to "fake bad", i.e. give the worst possible impression, as well as those instructed to be honest in their responses (e.g. Kuntz, 1974; Farley and Goh, 1976; Harvey and Sipprelle, 1976; Holden and Jackson, 1981; Burkhart, Christian and Gynther, 1978; Worthington and Schlottmann, 1986; Furnham and Craig, 1987). The results, while varying to some extent as a function of the specific inventory chosen, generally provide conclusive evidence: Most personality inventories, including standard instruments like the MMPI (Hathaway and McKinley, 1946), the EPQ (Eysenck and Eysenck, 1975), and the PRF (Jackson, 1967), consist of scales that are susceptible to faking and response biases which cast doubts on their utility as valid and reliable instruments in personality diagnostics. More specific faking instructions were examined in a study by Velicer and Weiner (1975). They instructed their subjects to complete the EPI from the point of view of a salesman, a librarian or their ideal self. A control group

*Address for correspondence: Department of Psychology, University of Mainz, Postfach 3980, D-6500 Mainz, Federal Republic of Germany. 
completed the EPI in line with their actual self. Significant differences in the E, N and L scores were found between the four groups in accordance with the faking instructions. Under the "salesman" perspective, for example, significantly higher scores on the extraversion scale were obtained than under the "librarian" instruction.

In the present study, the question is addressed whether subjects are capable of faking a specific personality profile on a multidimensional personality inventory rather than creating a global positive or negative impression. While faking "good" or "bad" requires subjects only to discriminate the socially desirable from the undesirable response alternatives, the manipulation of multidimensional personality inventories so as to create a particular image involves two more complex tasks:

(a) For each item, to identify correctly the response alternative which represents the intended image. The frame of reference for this task is not the general social desirability of the response alternatives but their desirability with regard to the respective image. The two standards may be conflicting and cause difficulties in cases where the socially undesirable response option (e.g. endorsing an "aggressive" answer) is desirable in terms of the intended profile (e.g. faking unsuitable for caring for old people).

(b) For the questionnaire as a whole, to distinguish those scales or clusters of items which are relevant to the intended image, and should be faked accordingly, from the irrelevant ones to which honest answers should be given. This task, in particular, requires respondents to have an implicit understanding of the dimensional structure of the questionnaire. They need to have a fairly precise idea of the correlational network underlying the different scales in order to be able to make a proper distinction between scales that are relevant and those that are irrelevant to the intended (faked) image.

Based on this line of reasoning, subjects in this study were presented with the case of a youth who faces a conflict between his or her own choice of career and their parents' ideas. A careers counsellor is allegedly called in for advice. He administers a personality questionnaire to the youth, who decides to complete it in such a way that the counsellor will subsequently back his or her preferred choice, e.g. taking vs not taking a degree in social work. Participants were instructed to put themselves in the position of the youth and complete the questionnaire from his or her point of view. This procedure was designed to examine the following hypotheses:

$\mathrm{H}_{1}$ : Individuals instructed to fake a specific personality image are capable of identifying the 'critical' scales and items in a standard personality inventory pertaining to the image in question.

$\mathrm{H}_{2}$ : They are further able to fake related scales in a way that is consistent with the intended image and reflects awareness of the correlational structure of the inventory.

\section{METHOD}

\section{Sample}

Seventy-two first-year undergraduates (29 males and 43 females) at the Erziehungswissenschaftliche Hochschule Landau, F.R.G., participated in the study. Participants came from various academic subjects, including psychology. The psychology students, who received experimental credit for their participation, had no prior knowledge of issues of personality diagnostics.

\section{Materials and procedure}

The personality inventory used to examine the hypotheses of the present study was the revised version of the Freiburger Persönlichkeitsinventar (FPI-R) by Fahrenberg, Hampel and Selg (1984). The FPI is a highly popular personality inventory in the German-speaking countries. It is used as a diagnostic instrument for a variety of purposes, such as personnel selection, careers guidance, and even decisions about returning the licence to drink and drive offenders. The revised version of the FPI consists of 12 scales listed in Table 1. With the exception of the $E$ and $N$ scales, which consist of 14 items, each scale is represented by 12 items to which respondents react in a forced-choice format. In the present study, two scales were selected as 'critical scales' for the faking manipulation: Scale 2, which measures Social Orientation in the sense of high vs. low social responsibility/solidarity; and Scale 3, which measures Achievement Orientation in the sense of high 
vs low ambition/competitiveness. Subjects were invited to participate in a study designed to measure the fakeability of personality inventories. When they arrived for the experiment, subjects were randomly assigned to one of four experimental groups. In the high social orientation (SO+) condition, they received the following instruction:

Please put yourself in Peter's position:

For the last six months, Peter has been working as a conscientious objector. His job has been to look after a group of mentally handicapped people sharing a flat. He likes the job so much that he decides to take a degree in social work. His father, who was not enthusiastic about his son's conscientious objection, is now completely outraged by this decision. He thinks that being a social worker is not a proper job for a man and wants his son to study computer science instead.

Peter wants to be diplomatic and suggests consulting a careers counsellor. Among other things, the careers counsellor asks Peter to complete the attached personality questionnaire.

Peter decides to complete the questionnaire in such a way that the counsellor will subsequently advise him to take up a course in social work. Please complete the attached questionnaire as if you were in Peter's situation. Try to create the image of being a person with a high social commitment. Please answer honestly all questions which are not related to this image.

In the low social orientation (SO-) condition, the first and last paragraphs of the above instruction were replaced by the following text:

Peter's mother runs a private old people's home. She has taken on the entire responsibility for the home after her husband's death and is dedicated to the work. Her wish is that Peter, her only son, takes a degree in social work to carry on with her life work after her death. Peter does not have the slightest interest in this kind of career. He wants to study computer science and has received high grades in the relevant "Leistungskurse" (A-levels) at school. [...]

Peter decides to complete the questionnaire in such a way that the counsellor will subsequently advise him against a course in social work. Please complete the attached questionnaire as if you were in Peter's situation. Try to create the image of being a person with a low social commitment. Please answer honestly all questions which are not related to this image.

In the remaining two conditions, subjects were instructed to fake FPI profiles with reference to achievement orientation. To control for sex effects, the protagonists in these conditions were described as females. In the high achievement orientation $(\mathrm{AO}+)$ condition, the instruction was changed as follows:

Please put yourself in Petra's position:

In six months' time, Petra will take her "Realschulabschluß" (O-levels). She is an ambitious and successful student and takes a special interest in mathematics and economics. After her O-levels, she wants to go on to business school and, possibly, university, because she would like one day to take over her father's company. Her father, however, wants his older son to take over the company. In his view, Petra, as a girl, will not have enough stamina to realise her plans. Moreover, he thinks that sooner or later she will get married and should then look after her family. Until then, he wants her to work in his company as a secretary. [...]

Petra decides to complete the questionnaire in such a way that the counsellor will subsquently advise her to continue her education. Please complete the attached questionnaire as if you were in Petra's situation. Try to create the image of being a person with a high achievement orientation. Please answer honestly all questions which are not related to this image.

Finally, in the low achievement orientation $(\mathrm{AO}-)$ condition, they received the following instruction:

According to her father's wish, Petra should read business administration at university to one day take over the family company. In contrast, Petra herself would like to be a sports teacher, as she values sufficient free time more highly than a career as company director. [...]

Petra decides to complete the questionnaire in such a way that the counsellor will subsequently advise her against a course in business administration. Please complete the attached questionnaire 
Table 1. Mean FPI scores of the four experimental groups

\begin{tabular}{|c|c|c|c|c|c|c|c|}
\hline & \multirow[b]{2}{*}{ FPI-Scale } & \multicolumn{6}{|c|}{ Faking instruction ${ }^{\mathrm{B}}$} \\
\hline & & $\begin{array}{c}\mathrm{SO}^{+} \\
(N=18)\end{array}$ & $\begin{array}{c}S^{-} \\
(N=18)\end{array}$ & $P$ & $\begin{array}{c}\mathrm{AO}^{+} \\
(N=18)\end{array}$ & $\begin{array}{c}\mathrm{AO}^{-} \\
(N=18)\end{array}$ & $P$ \\
\hline 1. & Life satisfaction & $5.61^{b}$ & 5.11 & n.s. & 6.17 & 4.56 & $<0.05$ \\
\hline 2. & Social orientation ${ }^{c}$ & 7.89 & 1.72 & $<0.001$ & 5.39 & 5.88 & n.s. \\
\hline 3. & Achievement orientation ${ }^{c}$ & 4.78 & 5.72 & $<0.05$ & 8.50 & 1.78 & $<0.001$ \\
\hline 4. & Inhibition & 3.89 & 5.72 & $<0.01$ & 2.61 & 5.89 & $<0.001$ \\
\hline 5. & Excitability & 2.61 & 5.33 & $<0.001$ & 3.22 & 5.33 & $<0.001$ \\
\hline 6. & Aggressiveness & 3.17 & 7.17 & $<0.001$ & 4.78 & 4.38 & n.s. \\
\hline 7. & Strain & 3.00 & 5.39 & $<0.001$ & 3.06 & 5.78 & $<0.001$ \\
\hline 8. & Somatic complaints & 2.06 & 2.28 & n.s. & 2.61 & 5.61 & $<0.001$ \\
\hline 9. & Health concern & 5.44 & 4.56 & n.s. & 5.50 & 5.11 & n.s. \\
\hline 10. & Openness & 3.22 & 6.55 & $<0.001$ & 3.28 & 5.61 & $<0.001$ \\
\hline $\mathbf{E}$ & Extraversion & 4.94 & 4.50 & n.s. & 6.50 & 3.28 & $<0.001$ \\
\hline $\mathbf{N}$ & Emotionality & 3.61 & 5.39 & $<0.01$ & 2.56 & 5.72 & $<0.001$ \\
\hline
\end{tabular}

${ }^{8} \mathrm{SO}^{+}=$high social orientation; $\mathrm{SO}^{-}=$low social orientation; $\mathrm{AO}^{+}=$high achievement orientation; $\mathrm{AO}^{-}=$low achievement orientation. bHigher means indicate more pronounced scores in the direction of the scale label.

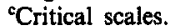

as if you were in Petra's situation. Try to create the image of being a person with a low achievement orientation. Please answer honestly all questions which are not related to this image.

After reading the instructions, all subjects completed the FPI and were subsequently dismissed. Following the collection of all data, subjects were fully informed about the aims of the study.

\section{RESULTS}

Each subject's FPI responses were coded in accordance with the standard scoring instructions. First, raw scores were established for each of the 12 scales. They were then transformed into Stanine (Standard Nine) scores based on the relevant norms (males and females aged between 16 and 24). To examine the hypotheses of the present study, the differences in mean Stanine scores between the $\mathrm{SO}^{+}$and $\mathrm{SO}^{-}$as well as $\mathrm{AO}^{+}$and $\mathrm{AO}^{-}$groups were tested through a series of $t$-tests. The results from these analyses are displayed in Table 1.

Looking first at the two critical scales, it is evident that highly significant differences emerged as a function of faking instruction. On the "social orientation" scale, the difference between the mean Stanine scores for the $\mathrm{SO}^{+}$group (7.89) and the $\mathrm{SO}^{-}$group (1.72) is highly significant $\left(t_{34}=13.55, P<0.001\right)$. The two means fall within the top and bottom $10 \%$ of the norm distribution. On the "achievement orientation" scale, the differences between the mean Stanine scores for the $\mathrm{AO}^{+}$group (8.50) and the $\mathrm{AO}^{-}$group (1.78) is also highly significant $\left(t_{34}=17.04\right.$, $P<0.001$ ). Again, the two means are within the top and bottom $10 \%$ of the norm distribution, indicating rather extreme scores.

While the two critical scales yield by far the largest differences in mean Stanine scores for their respective groups, Table 1 shows a number of additional scales for which significant differences have been found. The total number of scales affected by the faking instruction is substantial, suggesting that the FPI is an instrument that is relatively sensitive to response biases. An inspection of these scales suggests that subjects not only manipulated their responses to the critical scales in accordance with their instruction, but also faked related scales in a consistent way. Thus, subjects instructed to create the image of having a strong social orientation also portrayed themselves as significantly less aggressive, excitable, under strain, and emotionally unstable than subjects aiming to present themselves as having a low social orientation. In the same way, subjects creating a highly achievement-oriented image also portrayed themselves as less inhibited, excitable, under strain, emotionally unstable and prone to somatic complaints than those instructed to fake a low achievement orientation. Scales that have no obvious relevance to the faked image did not display significant differences.

The findings obtained for the "openness scale" deserve special attention. Both the $\mathrm{SO}^{+}$and the $\mathrm{AO}^{+}$groups score significantly lower on the openness scale than their $\mathrm{SO}^{-}$and $\mathrm{AO}^{-}$counterparts. Openness is interpreted by Fahrenberg et al. $(1984$, p. 34) as reflecting both a stable tendency towards unconventional behaviour and-in the case of low "openness" scores-a tendency towards 
Table 2. Rank correlations between scale intercorrelations for the norm population and the 4

\begin{tabular}{cccc}
\multicolumn{4}{c}{ experimental groups } \\
\hline $\mathrm{SO}^{+}$ & $\mathrm{SO}^{-}$ & $\mathrm{AO}^{+}$ & $\mathrm{AO}^{-}$ \\
\hline $0.65^{*}$ & $0.60^{*}$ & $0.70^{*}$ & $0.61^{*}$ \\
\hline${ }^{*} P<0.001$. & & &
\end{tabular}

response bias in the direction of social desirability. It may be argued that both $\mathrm{SO}^{+}$and $\mathrm{AO}^{+}$ represent more socially desirable images than their respective counterparts representing low social commitment and low achievement orientation. Accordingly, for the $\mathrm{SO}^{+}$and $\mathrm{AO}^{+}$groups, relatively lower scores on the openness scale are consistent with their instructions.

Thus, an inspection of the entire set of scales suggests that, as predicted in $\mathrm{H}_{2}$, subjects were successful in faking consistent personality profiles rather than individual scales. However, more precise evidence is needed to corroborate this interpretation. Therefore, the following line of reasoning was adopted. If one interprets the scale correlations reported in the FPI manual for the total norm population of $N=2035$ as a reliable index of the relationship between the 12 scales, then these intercorrelations provide information about which scales "go together" in the absence of any faking instruction. Accordingly, they can be used as a standard against which the scale intercorrelations obtained under the different faking instructions can be evaluated. To the extent that the latter correlations match the original pattern, it may be concluded that they reflect subjects' awareness of a consistent personality profile as well as its fakeability. To examine this proposition, the following procedure was employed: First, intercorrelations between the 12 scales were computed individually for each of the four groups. Second, the correlations obtained for the four groups were related to the original pattern of correlations on the basis of Spearman's rank coefficient. The results from these analyses are presented in Table 2.

These findings show that the rank order correlations between the scale intercorrelations obtained for the four experimental groups and those available for the original norm population are highly significant in each case. Thus, the scale intercorrelations obtained under the faking instructions closely resemble the intercorrelations obtained from the original norm population. It may be concluded that this close resemblance reflects the present subjects' implicit awareness of the correlational structure of the FPI, enabling them to fake a consistent personality profile.

\section{DISCUSSION}

The present results confirm the general hypothesis that laypersons have an intuitive understanding of the rationale of personality inventories which enables them to fake their scores deliberately. It was shown that they are able to manipulate their scores on the FPI so as to create a particular image. Subjects instructed to complete the questionnaire from the point of view of a person who wants to appear as having a high or low social commitment showed highly significant differences in their scores on the critical "social orientation" scale of the FPI. Similarly, subjects faking a person with a high or low achievement orientation differed significantly in their scores on the corresponding FPI scale. Moreover, respondents in each of the four groups manipulated related scales in a way that was consistent with the intended image. In so doing, they preserved the original relationships between the scales as reflected in the scale intercorrelations for the norm population. This is a clear indication that the subjects had an intuitive understanding of the correlational network underlying the inventory as a whole. In summary, the present findings suggest that the FPI is a diagnostic device whose purposes are highly transparent to the person under test. This is true not only for individual items or scales but also for the structure of the entire inventory (see also Semin, Rosch, Krolage and Chassein, 1981). In their manual, the test authors themselves have included a warning note that reflects their awareness of the problem: "Scale scores may be interpreted in psychological terms if neither the respondent's motivation to take the test nor the test situation give any reason for concern" (Fahrenberg et al., 1984, p. 46; translation by the author).

The present findings join a large body of earlier research demonstrating a variety of response biases and faking effects to which personality inventories are potentially prone. How serious, then, 
is the threat posed by these results to the reliability and validity of personality inventories? Or, to put it differently, is there any constructive information to be gained from this type of faking methodology? Turning to the latter question first, sympathetic critics have argued that the faking methodology may be used to elicit subjects' stereotypical conceptions about mental health and/or personality in general (e.g. Furnham, 1986). However the trouble is, at least as far as the present results are concerned, that subjects' stereotypical conceptions thus elicited correspond very closely to the professional psychologists' interpretations of the factor structure of their instruments. One might even be tempted to say that what subjects reveal as their stereotypes about personality is, in many cases, just what the researchers had in mind when they designed their instruments. A similar correspondence between scientific conceptions and lay conceptions of personality has been demonstrated for other aspects of personality theorising. Semin and Krahé (1987), for example, showed that even complex theoretical assumptions like Eysenck's propositions about phenotypic and genotypic differences between introverts and extraverts are available to laypersons (see also Smedslund, 1987). One of the implications of such findings is that it may be unwise to regard respondents as naive with respect to the underlying rationale of a personality test. Not only do they form hypotheses about the aims and purposes of a test they are asked to complete; often, their hypotheses are quite correct.

As far as issues of test reliability and validity are concerned, the consensual position appears to be that results from faking studies do indeed uncover potentially serious problems with many standard personality inventories. In terms of practical consequences, various responses have been suggested (cf. Furnham, 1986). One is to try and find means for detecting the existence and extent of faking in individual profiles, e.g. by including lie scales into the questionnaire. Eysenck and Eysenck (1974) have provided evidence that special "honesty" instructions, warning subjects that faking would be detected by the investigators, may serve to reduce the tendency, reflected in subjects' lie scores, to distort responses so as to create a more positive impression. A different strategy for detecting, if not reducing, the extent of faking in questionnaire responses has been suggested by Michaelis and Eysenck (1971). They demonstrated that subjects' motivation to present themselves favourably on a multidimensional questionnaire (the P.E.N.) systematically affects the scale intercorrelations. Compared with a "low motivation" group, negative correlations were shown to increase between the psychoticism (P) and lie (L) scales and to decrease between the extraversion $(\mathrm{E})$ and lie scales when subjects were motivated to do well on the questionnaire. Thus, substantial negative correlations between the $\mathrm{P}$ and $\mathrm{L}$ scales in conjunction with insignificant correlations between the $\mathrm{E}$ and $\mathrm{L}$ scales can be used as an indication that subjects have distorted their responses to the P.E.N. in the direction of positive self-presentation. Another approach has been to single out the critical determinants of response bias, such as a person's tendency to respond in a socially desirable way, and assess them in a separate scale. In sum, what these studies suggest is that it is possible for the investigator to find out, at least to some extent, whether or not subjects' responses to personality inventories reflect their true opinion of themselves. Nevertheless, this knowledge generally does not enable the investigator to 'purge' the obtained data, i.e. to extract the true personality profile from a response pattern identified as being distorted.

Therefore, a more radical or perhaps down-to-earth solution is to accept the fact that self-report inventories are susceptible to deliberate manipulations and that little can be done to the tests themselves which would make them less fakeable. Adopting this line of reasoning would involve placing much more emphasis than presently customary on understanding the respondent's motivation in completing the test. Quite often, there is a conflict of interest between the party administering the test and the person taking it, which may provide essential information. In a typical job selection situation, for instance, the employer's intention is to identify the most suitable candidate by discovering the strengths and weaknesses of each applicant. In contrast, the applicants' intention is to display their strengths and conceal their weaknesses as best they can. Thus, rather than asking whether and why a respondent may be motivated to manipulate his or her test response, it would appear more adequate to ask the reverse question: Why should respondents complete, in an honest, undistorted and ostensibly 'naive' way, a test whose aims are fully transparent to them and in whose outcome they often have a vested interest? In our view, a fruitful answer to this question would require that the traditional perspective on reliability and validity of personality inventories be broadened to include what may be called an interactionist 
approach to test taking. In such an approach, taking into account both the respondent's and the administrator's expectations of the information yielded by the test would have to become an integral part of the diagnostic situation.

\section{REFERENCES}

Berg I. A. (Ed.) (1967) Response Set in Personality Assessment. Aldine, Chicago.

Burkhart B., Christian W. and Gynther M. (1978) Item subtlety and faking on the MMPI: A paradoxical relationship. J. Person. Assess. 42, 76-80.

Eysenck H. J. and Eysenck S. B. G. (1975) The Eysenck Personality Questionnaire Manual. Hodder \& Stoughton, London

Eysenck S. B. G. and Eysenck H. J. (1974) The modification of personality and lie scale scores by special 'honesty' instructions. Br. J. soc. clin. Psychol. 13, 41-50.

Eysenck S. B. G., Nias D. and Eysenck H. J. (1971) The interpretation of children's lie scale scores. Br. J. educ. Psychol. 41, 23-31.

Fahrenberg J., Hampel R. and Selg H. (1984) Das Freiburger Persönlichkeitsinventar FPI, 4th rev. edn. Hogrefe, Göttingen.

Farley F. and Goh D. (1976) PENmanship: Faking the P-E-N. Br. J. soc. clin. Psychol. 15, 139-148.

Furnham A. (1986) Response bias, social desirability and dissimulation. Person. individ. Diff. 7, 385-400.

Furnham A. and Craig S. (1987) Fakeability and correlates of the perception and preference inventory. Person. individ. Diff. 8, 459-470.

Harvey M. A. and Sipprelle C. N. (1976) Demand characteristic effects on the subtle and obvious subscales of the MMPI J. Person. Assess. 40, 539-544.

Hathaway S. R. and McKinley J. C. (1946) Minnesota Multiphasic Personality Inventory. University of Minnesota Press, Minneapolis.

Holden R. and Jackson D. (1981) Item subtlety and face validity in personality assessment. J. clin. Psychol. 47, 379-386.

Jackson D. N. (1967) Personality Research Form Manual. Goshen, Research Psychologists Press, New York.

Kuntz D. (1974) Effects of faking instructions on the word-association test. Psychol. Rep. 35, 1183-1192.

Michaelis W. and Eysenck H. J. (1971) The determination of personality inventory factor patterns and intercorrelations by changes in real-life motivation. J. genet. Psychol. 118, 223-243.

Semin G. R., Rosch E., Krolage J. and Chassein J. (1981) Alltagswissen als implizite Basis für "wissenschaftliche" Persönlichkeitstheorien. Eine sozialpsychologische Analyse. Z. Sozialpsychol. 12, 233-242.

Semin G. R. and Krahé B. (1987) Lay conceptions of personality: Eliciting tiers of a scientific conception of personality. Eur. J. soc. Psychol, 17, 199-209.

Smedslund J. (1987) The epistemic status of inter-item correlations in Eysenck's Personality Questionnaire: The a priori versus the empirical in psychological data. Scand. J. Psychol. 28, 42-55.

Velicer W. and Weiner B. (1975) Effects of sophistication and faking sets on the Eysenck Personality Inventory. Psychol. Rep. 37, 71-73.

Wilcox R. and Krasnoff A. (1967) Influence of test-taking attitudes on personality inventory scores. J. consult. Psychol. 31, 188-194.

Worthington D. L. and Schlottmann R. S. (1986) The predictive validity of subtle and obvious empirically derived psychological test items under faking conditions. J. Person. Assess. 50, 171-181. 